\title{
Nonlinear Trajectory of Estimated GFR Progression in HIV- Positive Patients with Normal Renal Function on Tenofovir - based Therapy in Asia: a retrospective observational cohort study
}

Fang Liu

Xixi Hospital of Hangzhou

Aifang Xu

Xixi Hospital of Hangzhou

\section{Huaqing Zhao}

Temple University School of Medicine

Zongxing Yang

Xixi Hospital of Hangzhou

Chen Chen

Temple University

\section{Brona Ranieri}

Temple University

\section{Jianfeng Bao}

Xixi Hopital of Hangzhou

\section{Guoxiang Zheng}

Xixi Hospital of Hangzhou

Miaochan Wang

Xixi Hospital of Hangzhou

\section{Ying Wang}

Xixi Hospital of Hangzhou

Yunhao Xun ( $\nabla$ hzxxgb@outlook.com )

Xixi Hospital of Hangzhou

\section{Research article}

Keywords: Nonlinear Trajectory, Human Immunodeficiency Virus-1, Estimated Glomerular Filtration Rate, Renal Function, Tenofovir

Posted Date: August 2nd, 2019

DOI: https://doi.org/10.21203/rs.2.12361/v1

License: (c) (1) This work is licensed under a Creative Commons Attribution 4.0 International License. Read Full License 


\section{Abstract}

Background Estimated glomerular filtration rate (eGFR) trajectory in HIV-1-infected patients on tenofovir disoproxil fumarate (TDF) therapy has been widely estimated using linear models, but this linearity assumption is not well validated and the nonlinearity of eGFR change remains unknown in Asians with initially normal renal function. Methods Estimated GFR trajectories were compared by one-linear and piecewise-linear mixed effects models, before and after propensity matching, respectively. Whether the incidence of renal dysfunction (reduced renal function [RRF], eGFR $<90 \mathrm{~mL} / \mathrm{min} / 1.73 \mathrm{~m}^{2}$ and rapid kidney function decline [RKFD], eGFR $>-3 \mathrm{~mL} / \mathrm{min} / 1.73 \mathrm{~m}^{2} /$ year) follows nonlinearity was assessed by logistic regression. Results In this Chinese observational cohort, we examined 823 (299 of TDF users and 524 of non-TDF users) treatment-naïve HIV-1-infected participants (age $\geq 17$ years) with first eGFR greater than $90 \mathrm{~mL} / \mathrm{min} / 1.73 \mathrm{~m}^{2}$. The median follow-up time was 10 (interquartile range [IQR], 2-20) months, during which 178 (21.6\%) experienced RRF, and 451 (54.8\%) experienced RKFD. In nonlinear adjusted model, the eGFR of TDF users decreased over time before 1.40 years $\left(-5.31 \mathrm{~mL} / \mathrm{min} / 1.73 \mathrm{~m}^{2} /\right.$ year; $\left.95 \% \mathrm{Cl}:-6.57,-4.06\right)$, and after 2.30 years $\left(-3.71 \mathrm{~mL} / \mathrm{min} / 1.73 \mathrm{~m}^{2} /\right.$ year; $\left.95 \% \mathrm{Cl}:-5.97,-1.45\right)$. However, the eGFR significantly increased from years 1.40 to $2.30\left(4.83 \mathrm{~mL} / \mathrm{min} / 1.73 \mathrm{~m}^{2} /\right.$ year; $\left.95 \% \mathrm{Cl}: 1.38,8.28\right)$. Within this particular time frame, each year of TDF exposure was associated with a 78\% decreased risk of RKFD (95\% Cl: $-91 \%,-49 \%)$. In comparison, eGFR increased slightly at the initiation of antiviral therapy, declined after 2.15 years $\left(-4.96 \mathrm{~mL} / \mathrm{min} / 1.73 \mathrm{~m}^{2} /\right.$ year; $\left.95 \% \mathrm{Cl}:-5.76,-4.17\right)$ among nonTDF users. Such a progression nonlinear trajectory was missed on the assumption of one-linearity, whether in TDF or non-TDF users. Conclusion For HIV-1-infected Asians initiated antiviral therapy with normal renal function, the nonlinearity of renal function do exist. Routine screen based on nonlinear progression of eGFR could be helpful for clinical management and patient care.

\section{Background}

The widespread use of combination antiretroviral therapy (cART) has essentially improved the life expectancy of human immunodeficiency virus (HIV)-positive individuals [1]. However, lifelong use of potentially nephrotoxic antiretrovirals (ARVs), especially tenofovir disoproxil fumarate (TDF), can cause or exacerbate renal impairment [2,3]. Recent publications pay more attention to improve the quality of life in HIV-1 infected patients. Accomplishing this may necessitate alliances with anticipation, early detection of risk factors through routine screening to maintain renal toxicity vigilance.

Estimated glomerular filtration rate (eGFR) is a common indicator of renal function $[4,5]$. Studies have consistently demonstrated that TDF, as a conventional component of cART [6,7], is associated with a decline of eGFR and renal dysfunction in a subpopulation [8-13]. Delineating exactly the eGFR progression trajectories on TDF therapy through routine screening is undoubtedly helpful in this scenario. Since a linear figure seems convenient to interpret, most of the relevant studies so far considered the decline of eGFR to be approximated linear. The real trajectory of eGFR over time is however missed in these simplified model, thus hinders the optimization of TDF therapy in terms of renal function progression. In chronic kidney disease (CKD) population, several groups have reported nonlinear trajectories of eGFR in the past few years, its implications on risk estimation have gained interest and encouraged researchers to identify time dependent factors associated with this phenomenon in CKD with different origins [14-16]. However, no studies from HIV-1-positive patients have yet rigorously assessed the nonlinear changes of eGFR over time, especially in patients with normal eGFR on initiation of TDF-based antiviral therapy.

The objective of this study was to comprehensively analyze the trajectory of eGFR over time, and to compare the impact of regimens with or without TDF on this trajectory, in a Chinese cohort of treatment naïve HIV-1-positive 
individuals who initiated cART between Jan., 2010 and Dec., 2015. We also assessed the incidence of renal dysfunction based on nonlinear changes in eGFR, by using a two-piecewise logistic regression model.

\section{Methods}

\section{Study Population}

This is a retrospective, observational cohort study conducted at the Infectious Diseases Department (IDD) at Xixi Hospital (Hangzhou, Zhejiang, South China). All treatment naïve HIV-1-positive patients with records of cART initiation between January 26, 2010 and December 31, 2015 were screened for eligibility. A total of 1065 patients were enrolled as of January 26, 2017. This study was approved by the Institutional Review Board of Xixi Hospital.

\section{Data Collection and Inclusion Criteria}

Data extracted from the IDD database included demographic parameters, date of cART initiation, details of the cART regimens, route of HIV-1 transmission, comorbidities, and laboratory variables (HIV-1 RNA viral load, CD4 count, and serum creatinine [SCr]) at 2 weeks, 1 month, 2 months, 3 months, and every 3 months thereafter until January, 2017. Baseline was defined as the date of starting cART. Each enrolled patient was 17 years-old or more, had a normal baseline eGFR, and had at least one additional eGFR measurement since January, 2010. The flowchart was detailed in Fig.1.

\section{[Insert Fig.1]}

\section{Quantitative Variables}

The three-variable Modification of Diet in Renal Disease (MDRD) formula adjusted for Asian populations was used to calculate the eGFR values [17-19].

Combination ART was defined as the combined use of 3 or more ARVs from any drug class. Patients who took TDF alone or any TDF-containing regimen (TDF + lamivudine [3TC], or emtricitabine [FTC] + nevirapine [NVP], or efavirenz [EFV], or zidovudine [AZT]) were classified as TDF users. Patients exposed to any ARVs except TDF (AZT, or stavudine $[d 4 T]+3 T C+N V P$, or EFV) were classified as non-TDF users.

The two outcome definitions of this study were reduced renal function (RRF: eGFR $\geq 90 \mathrm{~mL} / \mathrm{min} / 1.73 \mathrm{~m}^{2}$ at baseline and eGFR $<90 \mathrm{~mL} / \mathrm{min} / 1.73 \mathrm{~m}^{2}$ during follow-up) [20], and rapid kidney function decline (RKFD: with progression to CKD; eGFR decline $>3 \mathrm{~mL} / \mathrm{min} / 1.73 \mathrm{~m}^{2} /$ year, estimated by least squares regression) [21].

\section{Statistical Analyses}

Baseline characteristics were recorded and compared between TDF users and non-TDF users, and electronically matched as necessary. Three models were used to analyze eGFR progression over time since ART initiation in each group (see Table 3). Model 1, the crude one, was not adjusted for any covariates. Model 2 was adjusted for age, sex, weight, height, body mass index (BMI), CD4 count, eGFR, dyslipidemia, HIV/AIDS risk factors (sexual orientation and intravenous drug use), WHO stage III/IV HIV/AIDS, hepatitis B positivity, hepatitis C positivity, anemia, diabetes, and HIV-1 RNA viral load. Model 3 used propensity score matching (PSM) to reduce preexisting imbalances in the 
covariates and potential confounding [22,23], and a covariate was considered well balanced when theP value was more than 0.05 (see Table 1), more technical details were as in additional Table S1.

The nonlinear trajectories of eGFR were determined by smooth curve fitting using a generalized additive model (GAM). Two methods were used to identify significant time points (inflection points on the smooth curves): one determined whether the difference of segmented slopes was equal to zero by the Wald test; the other applied a log likelihood ratio test to compare a nonlinear regression model with a one-linear regression model (see Table 2). Eventually, the time points were determined by constructing a maximum likelihood model using a recursion method. A two-piecewise linear mixed effects model, with random intercepts, was applied to quantify the average change per year of eGFR during different periods on cART (see Table 3). In addition, a two-piecewise logistic regression model based on Generalized Estimating Equation (GEE) was used to estimate the relationship of cART duration with RRF and with RKFD (see Table 4). All multivariate regression models were adjusted for the covariates used in Model 2.

Data on HIV-1 RNA viral load were not available in up to $50 \%$ of patients, so a missing value category was used in the main analyses $[24,25]$. In addition, to reduce bias caused by exclusion of individuals with any missing data at baseline, 5 imputed datasets (established by multiple imputation with chained equations) were developed and run separately, and the results were combined using Rubin's method [26,27] (see Additional file 1: Table S2, S3). Another sensitivity analysis was conducted to exclude patients receiving protease inhibitors (PIs), because of the possible association of these drugs with nephrotoxicity and impaired renal function [28-30] (see Additional file 1: Table S4, S5).

All analyses were performed using the R software, version 3.3.1 (http://www.R-project.org). A result was considered statistically significant when the two-tailed $\mathrm{P}$ value was below 0.05 .

\section{Results}

\section{Patient Selection and Propensity Score Matching}

As shown in the flowchart (Fig.1), a total of 1065 patients were enrolled and 823 patients were eligible for participation, 299 of whom (36.3\%) started a TDF-containing cART. Table 1 showed the baseline characteristics of TDF users and non-TDF users before and after PSM. After matching, there were 130 (33.3\%) patients in TDF group, and all baseline variables were well balanced $(P>0.05$ for all).

Of 823 patients, 178 (21.6\%) experienced RRF, and 451 (54.8\%) experienced RKFD. In TDF users, 97 experienced (32.4\%) RRF, and 183 (61.2\%) experienced RKFD. The median follow-up time was 10 (interquartile range [IQR], 2-20; maximum 90) months. The median age was 30 years among TDF users, and 27 years among non-TDF users. There were 4424 eGFR measurements for TDF users. For each group, there was a median of 7 eGFR measurements per person (IQR, 3-11) and the median interval between eGFR measurements was 90 (IQR, 30-90) days. Most enrolled patients were male and were infected via male-male sex.

\section{Main Analyses}

Comparison of one linear and piecewise linear mixed effects models.

We compared eGFR trajectories by one linear and piecewise linear models (see Table 2), with the piecewise model allowing a change of the eGFR slope at a given time point. Log likelihood ratio test between the two models indicated 
that nonlinear trajectory of eGFR was a better fit than the traditional one assuming a single linear process across the entire period of observation $(P<0.001$ for all).

Time points on nonlinear trajectories of eGFR.

For non-TDF users, the time points were 2.55 years (see Table 2, model 1), 2.15 years (see Table 2, model 2), and 2.15 years (see Table 2, model 3). The difference of eGFR slopes were $-4.79(-5.84,-3.74),-5.43(-6.47,-4.40)$ and $4.28(-6.24,-2.33)$, respectively.

For TDF users, the time points on nonlinear trajectory of eGFR were significantly different from that of non-TDF users. For example, the time points were 1.40 years and 2.30 years in model 2. The difference of eGFR slopes were -10.14 $(-14.44,-5.85)$ at 1.40 years and $-8.54(-12.67,-4.41)$ at 2.30 years. Similar results were obtained in other models (see Table 2).

The relationship between eGFR and duration of CART.

The eGFR changed over time in both groups (Fig.2, Additional file 1: Fig.S1, S2). There was a reverse S-shaped relationship between eGFR and duration of CART for TDF users, but a different temporal trajectory for non-TDF users, in all three models. The S-shaped trajectory was observed markedly in model 1 (Additional file 1: Fig.S1B) and model 2 (Fig.2B).

Average changes in eGFR over time on different CART duration among TDF or non-TDF users.

Table 3 showed average eGFR changes per year for the two groups according to cART duration. For TDF users, we obtained different results when the duration of cART was categorized using different time points in all three models. For cART less than 1.40 years, the $\exp (\beta)$ was -5.31 (95\% Cl: $-6.57,-4.06)$ and for 2.30 years or more was -3.71 $(95 \% \mathrm{Cl}:-5.97,-1.45)$. However, the $\exp (\beta)$ was $4.83(95 \% \mathrm{Cl}: 1.38,8.28)$ for 1.40 to 2.30 years. For models 1 and 3 , these time points were nearly the same, and similar trends were indicated in eGFR with increasing duration of cART (see Table 3).

For non-TDF users, before the time points, a longer duration of CART was associated with an increased eGFR in all three models; after the time points, there was an inverse association between eGFR and duration of cART. For model 1 , the $\exp (\beta)$ values and $95 \%$ Cls for eGFR change per year before and after the time point were $0.74(0.21,1.28)$ and $4.04(-4.72,-3.37)$, respectively; for model 2 these values were $0.47(0.00,0.94)$ and $-4.96(-5.76,-4.17)$; and for model 3 , these values were $0.77(-0.07,1.60)$ and $-3.51(-5.04,-1.99)$.

\section{Nonlinear progression of renal function over time.}

To assess whether renal dysfunction progression consists with the nonlinear trajectory of eGFR, we introduced two different outcome definitions, namely, RRF and RKFD (see Fig 4). For patients without TDF exposure, use of cART for 2.15 years or more, the risk of RRF increased steadily to 2.05 per year $(95 \% \mathrm{Cl}$ : 1.54, 2.71). For patients using TDF, there was an increased risk of RRF for those using cART less than 1.40 years (adjusted odds ratio [aOR]: 3.33 per year; 95\% Cl: $2.34,4.75$ ) and for using cART for 2.30 years or more (aOR: 1.58 per year; $95 \%$ Cl: $1.03,2.43$ ). However, those using TDF for 1.40 to 2.30 years had a lower risk of RRF ( $41 \%$ decrease per year; $95 \% \mathrm{Cl}:-75 \%, 39 \%$ ).

There was no increased risk of RKFD among non-TDF users who received cART for 2.15 years or more, nor among TDF users who received cART for less than 1.40 years. But, each additional one year of TDF exposure was associated with a $78 \%(95 \% \mathrm{Cl}:-91 \%,-49 \%)$ decreased risk of RKFD from 1.40 to 2.30 years, and a nearly 3-fold (95\% Cl: 1.08 , 
7.27) increased risk of RKFD for those on TDF for more than 2.30 years. Similar trends were observed in PSM data (see Table 4).

\section{Sensitivity Analyses}

Two sensitivity analyses, one conducted with imputed datasets and the other with patients not using Pls, indicated these results were robust (see Additional file 1: S2 to S5).

\section{Discussion}

This was the first study, to our knowledge, to investigate whether eGFR decline follows a nonlinear trajectory as renal dysfunction occurs, in HIV-1-positive patients initiating cART with normal eGFR. We present evidence from two analyses (the piecewise linear or logistic regression model) that the traditional assumption of a steady, linear decline does not apply to HIV-1 infected patients, especially those on TDF therapies. Our results showed that these patients experienced periods of acceleration or deceleration of kidney function decline. Analyses over nonlinear patterns speak to the true nature of the exposure-outcome relationships.

The comparison of one-linear and piecewise linear models suggested that nonlinear trajectory of eGFR was more accurate than a single linear process (log likelihood ratio test: $\mathrm{P}<0.001$ for all). When a single slope was fitted to the data, eGFR decline was either over- or under- estimated during partial period of CART. Intriguingly, nonlinear trajectories accurately depicted the periods of acceleration or deceleration of renal function decline, especially in TDF users who had an obvious heterogeneity in eGFR over time. This acceleration or deceleration, which was quantified by the piecewise linear mixed effects model, could be clearly identified from the data and smooth curves (see Table 3 and Fig.2). As illustrated for TDF users in model 2 (Fig.2), there was an increase of eGFR for intermediate cART durations (1.40-2.30 years), comparing markedly with the significant decline of eGFR either for short ( $<1.40$ years) or long cART durations ( $>2.30$ years). Certainly, these findings were similar in model 1 and model 3.

As expected, effects of nonlinearity of eGFR on renal dysfunction progression were well supported by the results of RRF and RKFD. In particular, the trends over time of RRF were completely consistent with nonlinear changes of eGFR (see Table 4). This finding was also robust, based on a range of sensitivity analyses.

Among TDF users, during the increasing period (1.40-2.30 years) of eGFR, the incidences of both outcomes, especially RKFD definitely declined (suggesting a recovery of renal function), even though TDF continued. This is consistent with previous studies suggested an overall limited effect of TDF on renal function decline. For example, a meta-analysis that compared ART regimens with or without TDF demonstrated a mean difference in eGFR of only $3.92 \mathrm{~mL} / \mathrm{min} / 1.73 \mathrm{~m}^{2}$ on a short-term follow-up [9]. Interestingly, a cohort study reported the cumulative decline of eGFR attributable to TDF was 3.05, 4.05 and $2.42\left(\mathrm{~mL} / \mathrm{min} / 1.73 \mathrm{~m}^{2}\right)$ at year $1,2,3$, respectively; this indicates that the eGFR decline attributable to TDF was lower 3 years after than that of before, suggesting a partial eGFR recovery from years 2 to 3 [20]. However, specific time points for renal function recovery are difficult to obtain by their one-linear analysis of eGFR.

We also found that continuous TDF exposure inevitably led to renal impairment in a substantial population. The incidence of RRF - but not the severe RKFD - increased during the initial use of TDF, incidences of both outcomes increased significantly later, suggesting that persistent TDF exposure can lead to cumulative and irreversible renal impairment, even in those with a normal baseline renal function. This was in agreement with that of the prospective international cohort study published recently, the increased incidence of CKD per year of exposure to TDF was initially small (14\%; $95 \%$ Cl: $10 \%, 19 \%)$, yet doubled for a treatment period of 5 years [2]. Regrettably, the authors used also the 
conventional linear analysis to address this issue, thereby the nonlinear trajectories of eGFR progression, if exist, remains unknown. As suggested by studies from CKD cohorts, linear regression methods do not exactly estimate kidney function trajectories [16], considering the big heterogeneity with respect to kidney function, dropout and number of kidney function estimates [31]. Nonlinear statistical methods, such as piecewise-linear mixed effects model [15], are able to better characterize the different profiles of renal function progression, as well as to investigate specific risk factors associated with each profile $[14,16]$. Therefore, our study provides a new avenue for this difficult task, at least in HIV patients with normal renal function, although having less-strength data. Future extra-validation with prospective international cohort like D:A:D Study would benefit a lot to characterize the real trajectories of eGFR progression, as well as the potential time window to salvage renal function and to investigate the underlying mechanisms of TDF related nephrotoxicity.

This present study has several implications for our understanding of renal dysfunction progression in HIV-1 infected patients during CART with initial normal renal function. First, periods of slight increasing eGFR followed by periods of eGFR decline and increasing risk of adverse events in non-TDF users suggesting that irrespective of the cART regimen (with or without TDF), loss of renal function to some extent seems inevitable following prolonged use of these drugs, especially after 2 years exposure or more. Screening frequencies on renal function should be planned according to this finding. Second, for TDF users, periods of rapid eGFR decline followed by periods of eGFR improvement, indicating that eGFR decline may sometimes be ameliorated over a given extended periods. One should aware of this early loss of renal function may not reflect future loss of renal function. The S-shaped nonlinear trajectory of eGFR may also open new avenues of diagnostic and treatment options so as to delay the progression of renal impairment among these long-term users of TDF.

This study has several strengths. First, the research has longitudinal data for up to 7 years of follow-up and regular eGFR assessments every 3 months for characterizing nonlinear trajectories of eGFR during cART. Second, by using of PSM, we were able to reduce confounding bias and balance the baseline characteristics of TDF exposure and nonexposure group. The results of this emulation of a randomized controlled trial were similar with model 1 and model 2 , suggesting that our findings were robust. Third, the time points suggested by our study were determined by a range of powerful statistical analyses (Wald test, piecewise linear mixed effects model along with maximum likelihood model and recursion method), together with two robust sensitivity analyses, thus is more accurate and powerful than the traditional paradigm based on clinical experience $[2,13,20]$.

Our study has several limitations. First, the inherent shortcomings belong to retrospective observational single-center study, small sample size and short term follow-up make it difficult to address the causality between TDF and CKD and reach a firm conclusion, the powerful statistical analysis thus is a trade-off to minimize these biases and confounding. Second, the patients in this study come exclusively from China, the findings may not simply apply to other populations and thus further validations from different races are warranted. Third, nonlinear trajectory of eGFR progression in patients complicated with CKD at baseline initiating TDF needs further investigation, after all, an interesting curve has already been identified by our population characterized by normal renal function. Fourth, this study did not investigate the predictive factors that may contribute to nonlinearity patterns of renal function, as well as TDF induced nephrotoxicity other than glomerular filtration function. All above limitations require further study to be overcome, nonetheless, our primary results provided moderate yet important illumination for this topic.

In conclusion, the present study suggests that renal function progression exists heterogeneity inHIV-positive patients with a normal eGFR initiating ART in Asians. There are significant differences in renal function trajectories between TDF and non-TDF therapy. Continuous TDF exposure inevitably led to renal impairment in a substantial population, but the changes of eGFR was inconsistent over time. An interesting reverse S-shaped nonlinear trajectory, the transient 
yet definitely recovery of renal impairment about 1.4 years after TDF initiation, do exist and could be helpful for the management of HIV-1-infected patients on TDF, which may provide a new avenue for patients care to improve the quality of their life.

\section{Additional Files}

Additional file 1: Table S1. Propensity score parameter list. Table S2. Predicted eGFR change rates in the piecewise linear mixed effects model in multiple imputation sample. Table S3. Association of antiretroviral exposure (in different time ranges) with risk of renal impairment outcomes in multiple imputation sample. Table S4. Predicted eGFR change rates among patients without receiving protease inhibitors in the piecewise linear mixed effects model. Table S5. Association of antiretroviral exposure (in different time ranges) with risk of renal impairment outcomes among patients without receiving protease inhibitors. Figure S1. Nonlinear trajectory of eGFR among HIV-1-infected patients with or without TDF in unadjusted model. Figure S2. Nonlinear trajectory of eGFR among HIV-1-infected patients with or without TDF in propensity score matched sample.

\section{Abbreviations}

TDF: Tenofovir disoproxil fumarate; eGFR: Estimated glomerular filtration rate; RRF: Reduced renal function; RKFD: Rapid kidney function decline; IQR: Interquartile range; HIV: Human immunodeficiency virus-1; ART: Antiretroviral therapy; CKD: Chronic kidney disease; IDD: Infectious diseases department; SCr: Serum creatinine; MDRD: Modification of diet in renal disease; ARVs: Antiretrovirals; 3TC: Lamivudine; FTC: Emtricitabine; NVP: Nevirapine; EFV: Efavirenz; AZT: Zidovudine; d4T: Stavudine; BMI: Body mass index; PSM: Propensity score matching; GAM: Generalized additive model; GEE: Generalized estimating equation; OR: Odds ratio; WHO: World health organization; NA: Not applicable; Cl: Confidence interval; MDR-TB: Multi-drug-resistant tuberculosis.

\section{Declarations}

\section{Acknowledgement}

We thank all study participants and staff of all participating sites.

\section{Funding}

The study did not need and was not funded.

\section{Availability of data and materials}

The data set used for this manuscript will be available from the corresponding author upon reasonable request.

\section{Authors' Contributors}

LF and XYH conceived, designed, and organised the study, interpreted the results, and drafted the manuscript. LF and $\mathrm{XYH}$ contributed equally to this manuscript. ZHQ analysed the data. YZX, CC, BR helped supervise the study, and revised the manuscript. The other authors contributed to collecting the data on site. 


\section{Ethics approval and consent to participate}

This study was approved by the Institutional Review Board of Xixi Hospital. All data were anonymized to comply with the provisions of personal data protection legislation. Due to the retrospective nature of this study and due the fact that only historical medical data were collected, written informed consent was not required.

\section{Consent for publication}

Not applicable

\section{Competing interests}

The authors declare that they have no competing interests.

\section{Author details}

${ }^{1}$ Medical Laboratory, Xixi Hospital of Hangzhou, Hangzhou, China; ${ }^{2}$ Temple University School of Medicine, Department of Clinical Sciences, Philadelphia, PA, USA; ${ }^{3}$ Department of Infectious Diseases, Xixi Hospital of Hangzhou, Hangzhou, China; ${ }^{4}$ Department of Neuroscience, Temple University, Philadelphia, PA, USA; ${ }^{5}$ Department of Integrated Chinese and Western Medicine, Xixi Hospital of Hangzhou, Hangzhou, China;

\section{References}

1.Nsanzimana S, Remera E, Kanters S, Chan K, Forrest JI, Ford N, Condo J, Binagwaho A, Mills EJ: Life expectancy among HIV-positive patients in Rwanda: a retrospective observational cohort study. LANCET GLOB HEALTH 2015, 3(3):e169-e177.

2.Mocroft A, Lundgren JD, Ross M, Fux CA, Reiss P, Moranne O, Morlat P, Monforte AD, Kirk O, Ryom L: Cumulative and current exposure to potentially nephrotoxic antiretrovirals and development of chronic kidney disease in HIV-positive individuals with a normal baseline estimated glomerular filtration rate: a prospective international cohort study. The Lancet HIV 2016, 3(1):e23-e32.

3.Atefeh J, Hossein K, Simin DK: Tenofovir-induced nephrotoxicity: incidence, mechanism, risk factors, prognosis and proposed agents for prevention. EUR J CLIN PHARMACOL 2014, 70(9):1029-1040.

4.Stevens LA, Coresh J, Greene T, Levey AS: Assessing kidney function-measured and estimated glomerular filtration rate. N Engl J Med 2006, 354(23):2473-2483.

5.Levin A, Stevens PE, Bilous RW, Coresh J, Francisco ALMD, Jong PED, Griffith KE, Hemmelgarn BR, Iseki K, Lamb EJ: Kidney disease: Improving global outcomes (KDIGO) CKD work group. KDIGO 2012 clinical practice guideline for the evaluation and management of chronic kidney disease. KIDNEY INT SUPPL 2013, 3(1):1-150.

6.Estrella MM, Moosa MR, Nachega JB: Editorial Commentary: Risks and Benefits of Tenofovir in the Context of Kidney Dysfunction in Sub-Saharan Africa. CLIN INFECT DIS 2014, 58(10):1481-1483.

7. Hirnschall G, Harries AD, Easterbrook PJ, Doherty MC, Ball A: The next generation of the World Health Organization's global antiretroviral guidance. J INT AIDS SOC 2013, 16(18757). 
8.Nishijima T, Kawasaki Y, Tanaka N, Mizushima D, Aoki T, Watanabe K, Kinai E, Honda H, Yazaki H, Tanuma J et al: Long-term exposure to tenofovir continuously decrease renal function in HIV-1-infected patients with low body weight: results from 10 years of follow-up. AIDS (London, England) 2014, 28(13):1903-1910.

9.Cooper RD, Wiebe N, Smith N, Keiser P, Naicker S, Tonelli M: Systematic Review and Meta-analysis: Renal Safety of Tenofovir Disoproxil Fumarate in HIV-Infected Patients. CLIN INFECT DIS 2010, 51(5):496-505.

10.Yombi JC, Pozniak A, Boffito M, Jones R, Khoo S, Levy J, Post FA: Antiretrovirals and the kidney in current clinical practice. AIDS 2014, 28(5):621-632.

11.Joshi K, Boettiger D, Kerr S, Nishijima T, Van Nguyen K, Ly PS, Lee MP, Kumarasamy N, Wong W, Kantipong P et al: Changes in renal function with long-term exposure to antiretroviral therapy in HIV-infected adults in Asia.

PHARMACOEPIDEM DR S 2018, 27(11):1209-1216.

12.Horberg M, Tang B, Towner W, Silverberg M, Bersoff-Matcha S, Hurley L, Chang J, Blank J, Quesenberry CJ, Klein D: Impact of tenofovir on renal function in HIV-infected, antiretroviral-naive patients. J Acquir Immune Defic Syndr 2010, 53(1):62-69.

13.De Waal R, Cohen K, Fox MP, Stinson K, Maartens G, Boulle A, Igumbor EU, Davies M: Changes in estimated glomerular filtration rate over time in South African HIV-1-infected patients receiving tenofovir: a retrospective cohort study. J INT AIDS SOC 2017, 20(2):B1.

14.Li L, Astor BC, Lewis J, Hu B, Appel LJ, Lipkowitz MS, Toto RD, Wang X, Wright JT, Greene TH: Longitudinal Progression Trajectory of GFR Among Patients With CKD. AM J KIDNEY DIS 2012, 59(4):504-512.

15.Zhong Y, Munoz A, Schwartz GJ, Warady BA, Furth SL, Abraham AG: Nonlinear trajectory of GFR in children before RRT. J AM SOC NEPHROL 2014, 25(5):913-917.

16.Weldegiorgis M, de Zeeuw D, Li L, Parving HH, Hou FF, Remuzzi G, Greene T, Heerspink H: Longitudinal Estimated GFR Trajectories in Patients With and Without Type 2 Diabetes and Nephropathy. AM J KIDNEY DIS 2018, 71(1):91101.

17.Shi $\mathrm{H}$, Chen $\mathrm{N}$, Zhang W: Evaluating and refitting the simplified equation of MDRD to predict glomerular filtration rate in Chinese patients with chronic kidney disease. Chinese Journal of Practical Internal Medicine 2006, 26(9):665669.

18.Liu X, Qiu X, Shi C, Huang H, Huang J, Li M, Lou T: Modified Glomerular Filtration Rate-Estimating Equations Developed in Asiatic Population for Chinese Patients with Type 2 Diabetes. INT J ENDOCRINOL 2014, 2014:1-9.

19.Chang $\mathrm{H}$, Tan M: Application of modified glomerular filtration rate(GFR) estimation equations in Chinese diabetic patients with chronic kidney disease in diabetes. West Indian Medical Journal 2015, 64(3):209.

20.Laprise C, Baril JG, Dufresne S, Trottier H: Association Between Tenofovir Exposure and Reduced Kidney Function in a Cohort of HIV-Positive Patients: Results From 10 Years of Follow-up. CLIN INFECT DIS 2013, 56(4):567-575.

21.Zachor H, Machekano R, Estrella MM, Veldkamp PJ, Zeier MD, Uthman OA, Taljaard JJ, Moosa MR, Nachega JB: Incidence of stage 3 chronic kidney disease and progression on tenofovir-based regimens. AIDS 2016, 30(8):12211228. 
22.Dehejia RH, Wahba S: Propensity Score-Matching Methods for Nonexperimental Causal Studies. REV ECON STAT 2002, 84(1):151-161.

23.Austin PC: Primer on Statistical Interpretation or Methods Report Card on Propensity-Score Matching in the Cardiology Literature From 2004 to 2006. Circulation: Cardiovascular Quality and Outcomes 2008, 1(1):62-67.

24.Erviti J, Alonso Á, Oliva B, Gorricho J, López A, Timoner J, Huerta C, Gil M, De Abajo F: Oral bisphosphonates are associated with increased risk of subtrochanteric and diaphyseal fractures in elderly women: a nested case-control study. BMJ OPEN 2013, 3(1):e2091.

25.D"Agostinojr. R, Rubin D: Estimating and Using Propensity Scores with Partially Missing Data. Publications of the American Statistical Association 2000, 95(451):749-759.

26.White IR, Patrick R, Wood AM: Multiple imputation using chained equations: Issues and guidance for practice. STAT MED 2011, 30(4):377-399.

27.Toutenburg H: Rubin, D. B.: Multiple imputation for nonresponse in surveys. STAT PAP 1990, 31(1):180.

28.Young J, Schäfer J, Fux CA, Furrer H, Bernasconi E, Vernazza P, Calmy A, Cavassini M, Weber R, Battegay M et al: Renal function in patients with HIV starting therapy with tenofovir and either efavirenz, lopinavir or atazanavir. AIDS (London, England) 2012, 26(5):567-575.

29.Ryom L, Mocroft A, Kirk O, Worm SW, Kamara DA, Reiss P, Ross M, Fux CA, Morlat P, Moranne O et al: Association Between Antiretroviral Exposure and Renal Impairment Among HIV-Positive Persons With Normal Baseline Renal Function: the D:A:D Studya. J INFECT DIS 2013, 207(9):1359-1369.

30.Kearney BP, Mathias A, Mittan A, Sayre J, Ebrahimi R, Cheng AK: Pharmacokinetics and safety of tenofovir disoproxil fumarate on coadministration with lopinavir/ritonavir. J Acquir Immune Defic Syndr 2006, 43(3):278-283.

31.Janmaat CJ, van Diepen M, Tsonaka R, Jager KJ, Zoccali C, Dekker FW: Pitfalls of linear regression for estimating slopes over time and how to avoid them by using linear mixed-effects models. NEPHROL DIAL TRANSPL 2018.

\section{Tables}

Table 1. Characteristics at cohort entry stratified by Tenofovir Disoproxil Fumarate before and after propensity score matching. 


\begin{tabular}{|c|c|c|c|c|c|c|}
\hline \multirow[b]{2}{*}{ Characteristic } & \multicolumn{3}{|c|}{ Before matching } & \multicolumn{3}{|c|}{ After matching } \\
\hline & Without TDF & With TDF & $\begin{array}{l}P \\
\text { value }\end{array}$ & Without TDF & With TDF & $\begin{array}{l}P \\
\text { value }\end{array}$ \\
\hline Overall & $(\mathrm{n}=524,63.7 \%)$ & $(n=299,36.3 \%)$ & & $(\mathrm{n}=260,66.7 \%)$ & $(n=130,33.3 \%)$ & \\
\hline Age (years) & $27(24-32)$ & $30(25-36)$ & $<0.001$ & $27(25-32)$ & $27(25-33)$ & 0.638 \\
\hline Female & $20(3.8 \%)$ & $18(6.0 \%)$ & 0.147 & $5(1.9 \%)$ & 5 ( $3.8 \%)$ & 0.428 \\
\hline Weight (kg) & $63(57-70)$ & $63(56-67)$ & 0.185 & $62(57-70)$ & $63(58-68)$ & 0.810 \\
\hline Height (cm) & $172(169-175)$ & $172(169-175)$ & 0.546 & $172(170-175)$ & $172(170-175)$ & 0.790 \\
\hline BMI (kg/m】) & $\begin{array}{l}21.1(19.5- \\
23.1)\end{array}$ & $\begin{array}{l}21.0(19.4- \\
22.7)\end{array}$ & 0.240 & $\begin{array}{l}21.0(19.4- \\
23.1)\end{array}$ & $\begin{array}{l}21.2(19.5- \\
22.9)\end{array}$ & 0.637 \\
\hline $\begin{array}{l}\text { CD4 (cells/ } \\
\mu L)\end{array}$ & $323(246-423)$ & 247 (117-359) & $<0.001$ & $326(262-420)$ & $335(246-414)$ & 0.988 \\
\hline $\begin{array}{l}\text { Triglycerides } \\
\text { (mmol/L) }\end{array}$ & $1.1(0.8-1.7)$ & $1.3(0.9-1.7)$ & 0.715 & $1.2(0.8-1.7)$ & $1.2(0.8-1.7)$ & 0.739 \\
\hline $\begin{array}{l}\text { Total } \\
\text { cholesterol } \\
(\mathrm{mmol} / \mathrm{L})\end{array}$ & $4.0(3.5-4.5)$ & $3.8(3.3-4.4)$ & 0.006 & $4.0(3.5-4.5)$ & $3.9(3.5-4.4)$ & 0.676 \\
\hline $\begin{array}{l}\text { eGFR } \\
(\mathrm{mL} / \mathrm{min} \\
\text { per1.73m } \square)\end{array}$ & $111(102-121)$ & $112(103-126)$ & 0.426 & $112(101-122)$ & $111(103-120)$ & 0.767 \\
\hline Dyslipidemia & 72 (13.7\%) & $42(14.0 \%)$ & 0.879 & $34(13.1 \%)$ & $17(13.1 \%)$ & 1.000 \\
\hline Risk factor & & & 0.005 & & & 0.689 \\
\hline Homosexual & $\begin{array}{l}413(78.8 \%) \\
69(13.2 \%)\end{array}$ & $\begin{array}{l}203(67.9 \%) \\
60(20.1 \%)\end{array}$ & & $\begin{array}{l}205(78.8 \%) \\
31(11.9 \%)\end{array}$ & $\begin{array}{l}100(76.9 \%) \\
20(15.4 \%)\end{array}$ & \\
\hline Heterosexual & & & & & & \\
\hline $\begin{array}{l}\text { Injection } \\
\text { drug user }\end{array}$ & $1(0.2 \%)$ & $0(0.0 \%)$ & & $1(0.4 \%)$ & $0(0.0 \%)$ & \\
\hline Other & 41 ( $7.8 \%)$ & $36(12.0 \%)$ & & 23 ( 8.8\%) & $10(7.7 \%)$ & \\
\hline $\begin{array}{l}\text { WHO stage } \\
\text { III/IV }\end{array}$ & $84(16.0 \%)$ & 103 (34.4\%) & $<0.001$ & 31 (11.9\%) & $13(10.0 \%)$ & 0.692 \\
\hline $\begin{array}{l}\text { Hepatitis B } \\
\text { status }\end{array}$ & & & $<0.001$ & & & NA \\
\hline Positive & $9(1.7 \%)$ & $43(14.4 \%)$ & & $0(0.0 \%)$ & $0(0.0 \%)$ & \\
\hline
\end{tabular}




$\begin{array}{lllll}\text { Negative } & 476(90.8 \%) & 236(78.9 \%) & 260(100.0 \%) & 130(100.0 \%) \\ \text { Unknown } & 39(7.4 \%) & 20(6.7 \%) & 0(0.0 \%) & 0(0.0 \%)\end{array}$

Hepatitis C

0.003

NA

status

\begin{tabular}{|c|c|c|c|c|c|c|}
\hline Positive & $3(0.6 \%)$ & 11 ( $3.7 \%)$ & & $0(0.0 \%)$ & $0(0.0 \%)$ & \\
\hline Negative & 472 (90.1\%) & 255 (85.3\%) & & 260 (100.0\%) & $130(100.0 \%)$ & \\
\hline Unknown & 49 ( $9.4 \%)$ & 33 (11.0\%) & & $0(0.0 \%)$ & $0(0.0 \%)$ & \\
\hline Anaemia & $11(2.1 \%)$ & $40(13.4 \%)$ & $<0.001$ & $3(1.2 \%)$ & $0(0.0 \%)$ & 0.539 \\
\hline Diabetes & $16(3.1 \%)$ & $10(3.3 \%)$ & 0.818 & $8(3.1 \%)$ & $2(1.5 \%)$ & 0.571 \\
\hline $\begin{array}{l}\text { Viral load } \\
\text { (copies per }\end{array}$ & & & 0.012 & & & 0.712 \\
\hline $\mathrm{mL})$ & & & & & & \\
\hline$<400$ & $39(7.4 \%)$ & 17 ( $5.7 \%)$ & & $26(10.0 \%)$ & $9(6.9 \%)$ & \\
\hline $\begin{array}{r}\geq 400 \\
<10000\end{array}$ & $127(24.2 \%)$ & 45 (15.1\%) & & 65 (25.0\%) & 29 (22.3\%) & \\
\hline $\begin{array}{l}\geq 10000 \\
<100000\end{array}$ & 92 (17.6\%) & 56 (18.7\%) & & 49 (18.8\%) & 23 (17.7\%) & \\
\hline$\geq 100000$ & $29(5.5 \%)$ & 15 ( $5.0 \%)$ & & $15(5.8 \%)$ & $8(6.2 \%)$ & \\
\hline Unknown & 237 (45.2\%) & 166 (55.5\%) & & 105 (40.4\%) & 61 (46.9\%) & \\
\hline Protease & $8(1.5 \%)$ & 34 (11.4\%) & $<0.001$ & $2(0.1 \%)$ & $1(0.1 \%)$ & 1.000 \\
\hline
\end{tabular}

Data are $\mathrm{n}(\%)$ or median (IQR) unless otherwise indicated. Baseline was defined as the date of starting antiretroviral therapy on or after January, 2010. After matching, P value > 0.05 indicates a relatively small baseline imbalance between TDF and non-TDF users. Diabetes and dyslipidemia defined by the diagnosis or related medication. Anemia was defined as hemoglobin $<12.0 \mathrm{~g} / \mathrm{dL}$ in women and $<13.0 \mathrm{~g} / \mathrm{dL}$ in men. Coinfection with hepatitis B defined by positive hepatitis B surface antigen, coinfection with hepatitis C defined by positive HCV viral load. 
Table 2. The difference of slopes before and after cutoff-times and comparison of one-linear and piecewise model. 


\section{Model 1}

\begin{tabular}{llll}
$\begin{array}{l}\text { Comparison of } \\
\text { slopes }\end{array}$ & $\operatorname{Exp}(\beta)^{\mathrm{a}}(95 \% \mathrm{CI})$ & $\begin{array}{l}\text { Comparison of } \\
\text { slopes }\end{array}$ & $\operatorname{Exp}(\beta)^{\mathrm{a}}(95 \% \mathrm{CI})$ \\
\hline$<2.55 \mathrm{y}$ & $-4.79(-5.84,-3.74)$ & $<1.40 \mathrm{y}$ & $-8.47(-11.56,-5.37)$ \\
$\geq 2.55 \mathrm{y}$ & $<0.001$ & $\geq 1.40 \mathrm{y},<3.20 \mathrm{y}$ & $<0.001$ \\
\hline $\begin{array}{l}\text { Comparison of } \\
\text { models }\end{array}$ & $\begin{array}{l}\text { Log likelihood ratio } \\
\text { test }^{\mathrm{b}}\end{array}$ & $\begin{array}{l}\text { Comparison of } \\
\text { slopes }\end{array}$ & \\
One-linear model & $<0.001$ & $\geq 1.40 \mathrm{y},<3.20 \mathrm{y}$ & $-9.22(-12.52,-5.92)$ \\
Non-linear model & & $\geq 3.20 \mathrm{y}$ & $<0.001$
\end{tabular}

Comparison of models Log likelihood ratio test ${ }^{\mathrm{b}}$

One-linear model $\quad<0.001$

Non-linear model

\section{Model 2}

\begin{tabular}{ll}
$\begin{array}{l}\text { Comparison of } \\
\text { slopes }\end{array}$ & $\operatorname{Exp}(\beta)^{\mathrm{a}}(95 \% \mathrm{CI})$ \\
\hline$<2.15$ y & $\begin{array}{l}-5.43(-6.47,-4.40) \\
\geq 0.001\end{array}$ \\
$\geq 2.15 \mathrm{y}$ & $\begin{array}{l}\text { Log likelihood ratio } \\
\text { test }^{\mathrm{b}}\end{array}$ \\
\hline $\begin{array}{l}\text { Comparison of } \\
\text { models }\end{array}$ & $<0.001$ \\
\hline One-linear model &
\end{tabular}

$\begin{array}{ll}\begin{array}{l}\text { Comparison of } \\ \text { slopes }\end{array} & \operatorname{Exp}(\beta)^{\mathrm{a}}(95 \% \mathrm{CI}) \\ <1.40 \mathrm{y} & -10.14(-14.44,-5.85) \\ \geq 1.40 \mathrm{y},<2.30 \mathrm{y} & <0.001\end{array}$

Comparison of slopes
$\geq 1.40 \mathrm{y},<2.30 \mathrm{y} \quad-8.54(-12.67,-4.41)$ $<0.0001$

$\geq 2.30 \mathrm{y}$
Comparison of models One-linear model $\quad<0.001$
Log likelihood ratio test ${ }^{b}$

Non-linear model

\section{Model 3}

$\begin{array}{ll}\begin{array}{l}\text { Comparison of } \\ \text { slopes }\end{array} & \operatorname{Exp}(\beta)^{\mathrm{a}}(\mathbf{9 5 \%} \mathrm{CI}) \\ <2.15 \mathrm{y} & -4.28(-6.24,-2.33) \\ \geq 2.15 \mathrm{y} & <0.001\end{array}$

Comparison of models

One-linear model Non-linear model

\section{Log likelihood ratio} test $^{\mathrm{b}}$ $<0.001$
Comparison of slopes

$<1.30 \mathrm{y}$

$\geq 1.30 \mathrm{y},<2.10 \mathrm{y}$

Comparison of slopes

$\geq 1.30 \mathrm{y},<2.10 \mathrm{y} \quad-8.82(-14.89,-2.76) 0.004$

$\geq 2.10 \mathrm{y}$

Comparison of models

One-linear model

Non-linear model
$\operatorname{Exp}(\beta)^{\mathrm{a}}(95 \% \mathrm{CI})$

-7.09 (-13.99, -0.20) 0.044 
b: Log likelihood ratio test was used to compare one-linear regression model with two piecewise regression model, below 0.05 indicates two piecewise regression model was a better fit to the data than the one-linear model that assumed a single slope across the entire period of observation.

Table 3. Predicted eGFR change rates in the piecewise linear mixed effects model. 


\begin{tabular}{|c|c|c|c|c|c|}
\hline & \multicolumn{2}{|c|}{ Without TDF } & & \multicolumn{2}{|l|}{ With TDF } \\
\hline & $\operatorname{Exp}(\beta)(95 \% \mathrm{CI})$ & $P$ value & & $\operatorname{Exp}(\beta)(95 \% \mathrm{CI})$ & $P$ value \\
\hline \multicolumn{6}{|l|}{ Model 1} \\
\hline Time as linear & $-1.29(-1.58$ & $<0.001$ & Time as linear trend & $-1.46(-1.94,-0.98)$ & $<0.001$ \\
\hline trend & $-1.00)$ & & & & \\
\hline Fitted Groups & & & Fitted Groups & & \\
\hline$<2.55 \mathrm{y}$ & $0.74(0.21,1.28)$ & 0.006 & $<1.40 \mathrm{y}$ & $-4.73(-6.09,-3.37)$ & $<0.001$ \\
\hline \multirow[t]{2}{*}{$\geq 2.55 \mathrm{y}$} & $-4.04(-4.72$ & $<0.001$ & $\geq 1.40 \mathrm{y},<3.20 \mathrm{y}$ & $3.74(1.64,5.84)$ & 0.004 \\
\hline & $-3.37)$ & & & & \\
\hline-- & -- & -- & $\geq 1.40 \mathrm{y}$ & $-5.48(-8.03,-2.93)$ & $<0.001$ \\
\hline \multicolumn{6}{|l|}{ Model 2} \\
\hline Time as linear & $-1.20(-1.54$ & $<0.001$ & Time as linear trend & $-2.56(-3.19,-1.94)$ & $<0.001$ \\
\hline trend & $-0.85)$ & & & & \\
\hline Fitted Groups & & & Fitted Groups & & \\
\hline$<2.15 \mathrm{y}$ & $0.47(0.00,0.94)$ & 0.049 & $<1.40 \mathrm{y}$ & $-5.31(-6.57,-4.06)$ & $<0.001$ \\
\hline \multirow[t]{2}{*}{$\geq 2.15 \mathrm{y}$} & $-4.96(-5.76$ & $<0.001$ & $\geq 1.40 \mathrm{y},<2.30 \mathrm{y}$ & $4.83(1.38,8.28)$ & 0.006 \\
\hline & $-4.17)$ & & & & \\
\hline-- & -- & - & $\geq 2.30 \mathrm{y}$ & $-3.71(-5.97,-1.45)$ & 0.001 \\
\hline
\end{tabular}

\section{Model 3}

Time as linear $-0.47(-1.09,0.15) \quad 0.139 \quad$ Time as linear trend $-1.77(-2.60,-0.94)<0.001$ trend

Fitted Groups Fitted Groups

\begin{tabular}{llllll}
$<2.15 \mathrm{y}$ & $0.77(-0.07,1.60)$ & $0.072<1.30 \mathrm{y}$ & $-2.78(-4.73,-0.83)$ & 0.005 \\
\hline $22.15 \mathrm{y}$ & $-3.51(-5.04$, & $<0.001$ & $\geq 1.30 \mathrm{y},<2.10 \mathrm{y}$ & $4.31(-1.28,9.90)$ & 0.131 \\
& $-1.99)$ & & & & \\
& -- & - & $\geq 2.10 \mathrm{y}$ & $-4.51(-6.86,-2.17)$ & $<0.001$ \\
\hline
\end{tabular}

Abbreviations: $\operatorname{Exp}(\beta)$, the rate of change in eGFR per year, obtained with the interaction term between TDF using status and time since cART initiation.

Model 1: unadjusted for any variables at baseline. 
Model 2: adjusted for age, sex, weight, height, body mass index (BMI), CD4 count, eGFR, dyslipidemia, HIV/AIDS risk factors (sexual orientation and intravenous drug use), WHO stage III/IV HIV/AIDS, hepatitis B positivity, hepatitis C positivity, anemia, diabetes, and HIV-1 RNA viral load at baseline. Model 3: propensity score matched sample.

Table 4. Association of antiretroviral exposure (in different time ranges) with risk of renal impairment outcomes. 


\begin{tabular}{|c|c|c|c|c|c|}
\hline \multicolumn{6}{|c|}{ Unmatched Sample $^{\mathrm{a}}$} \\
\hline & \multicolumn{2}{|c|}{ Without TDF } & & \multicolumn{2}{|c|}{ With TDF } \\
\hline & OR $(95 \% \mathrm{CI})$ & $\begin{array}{l}P \\
\text { value }\end{array}$ & & OR $(95 \% \mathrm{CI})$ & $\begin{array}{l}P \\
\text { value }\end{array}$ \\
\hline \multicolumn{6}{|l|}{ Reduced Kidney } \\
\hline \multicolumn{6}{|l|}{ Function $^{b}$} \\
\hline Time as linear trend & $\begin{array}{l}1.67(1.42, \\
1.98)\end{array}$ & $<0.001$ & $\begin{array}{l}\text { Time as linear } \\
\text { trend }\end{array}$ & $1.80(1.54,2.09)$ & $<0.001$ \\
\hline Fitted Groups & & & Fitted Groups & & \\
\hline$<2.15 \mathrm{y}$ & $\begin{array}{l}1.33(0.97, \\
1.81)\end{array}$ & 0.074 & $<1.40 \mathrm{y}$ & $3.33(2.34,4.75)$ & $<0.001$ \\
\hline$\geq 2.15 \mathrm{y}$ & $\begin{array}{l}2.05(1.54, \\
2.71)\end{array}$ & $<0.001$ & $\geq 1.40 \mathrm{y},<2.30 \mathrm{y}$ & $0.59(0.25,1.39)$ & 0.229 \\
\hline-- & -- & -- & $\geq 2.30 \mathrm{y}$ & $1.58(1.03,2.43)$ & 0.035 \\
\hline \multicolumn{6}{|c|}{ Rapid Kidney Function Decline ${ }^{c}$} \\
\hline Time as linear trend & $\begin{array}{l}0.91(0.84 \\
0.98)\end{array}$ & 0.020 & $\begin{array}{l}\text { Time as linear } \\
\text { trend }\end{array}$ & $1.05(0.93,1.18)$ & 0.418 \\
\hline Fitted Groups & & & Fitted Groups & & \\
\hline$<2.15 \mathrm{y}$ & $\begin{array}{l}0.89(0.80 \\
1.00)\end{array}$ & 0.048 & $<1.40 \mathrm{y}$ & $1.07(0.87,1.32)$ & 0.512 \\
\hline$\geq 2.15 \mathrm{y}$ & $\begin{array}{l}0.94(0.77, \\
1.14)\end{array}$ & 0.524 & $\geq 1.40 \mathrm{y},<2.30 \mathrm{y}$ & $0.22(0.09,0.51)$ & $<0.001$ \\
\hline-- & -- & -- & $\geq 2.30 \mathrm{y}$ & $2.80(1.08,7.27)$ & 0.034 \\
\hline \multicolumn{6}{|c|}{ Matched Sample $^{\mathrm{d}}$} \\
\hline & \multicolumn{2}{|c|}{ Without TDF } & & \multicolumn{2}{|c|}{ With TDF } \\
\hline & OR $(95 \% \mathrm{CI})$ & $\begin{array}{l}\mathrm{P} \\
\text { value }\end{array}$ & & OR $(95 \% \mathrm{CI})$ & $\begin{array}{l}P \\
\text { value }\end{array}$ \\
\hline \multicolumn{6}{|c|}{ Reduced Kidney Function ${ }^{b}$} \\
\hline Time as linear trend & $\begin{array}{l}1.38(1.12, \\
1.70)\end{array}$ & 0.003 & $\begin{array}{l}\text { Time as linear } \\
\text { trend }\end{array}$ & $1.49(1.25,1.78)$ & $<0.001$ \\
\hline Fitted Groups & & & Fitted Groups & & \\
\hline
\end{tabular}




\begin{tabular}{|c|c|c|c|c|c|}
\hline$<2.15 \mathrm{y}$ & $\begin{array}{l}1.23(0.84, \\
1.79)\end{array}$ & 0.287 & $<1.30 \mathrm{y}$ & $2.62(1.50,4.59)$ & $<0.001$ \\
\hline$\geq 2.15 \mathrm{y}$ & $\begin{array}{l}1.54(1.08, \\
2.20)\end{array}$ & 0.017 & $\geq 1.30 \mathrm{y},<2.10 \mathrm{y}$ & $0.56(0.14,2.33)$ & 0.429 \\
\hline-- & -- & -- & $\geq 2.10 y$ & $1.34(0.90,1.99)$ & 0.152 \\
\hline \multicolumn{6}{|c|}{ Rapid Kidney Function Decline ${ }^{c}$} \\
\hline Time as linear trend & $\begin{array}{l}1.01(0.92, \\
1.11)\end{array}$ & 0.834 & $\begin{array}{l}\text { Time as linear } \\
\text { trend }\end{array}$ & $1.15(0.99,1.34)$ & 0.064 \\
\hline Fitted Groups & & & Fitted Groups & & \\
\hline$<2.15 \mathrm{y}$ & $\begin{array}{l}0.94(0.82, \\
1.08)\end{array}$ & 0.396 & $<1.30 \mathrm{y}$ & $1.19(0.87,1.62)$ & 0.275 \\
\hline$\geq 2.15 \mathrm{y}$ & $\begin{array}{l}1.17(0.94, \\
1.45)\end{array}$ & 0.171 & $\geq 1.30 \mathrm{y},<2.10 \mathrm{y}$ & $0.19(0.07,0.56)$ & 0.002 \\
\hline-- & -- & -- & $\geq 2.10 \mathrm{y}$ & $\begin{array}{l}12.43(0.78 \\
197.43)\end{array}$ & 0.074 \\
\hline
\end{tabular}

a: Represents the model adjusted for age, sex, weight, height, body mass index (BMI), CD4 count, eGFR, dyslipidemia, HIV/AIDS risk factors (sexual orientation and intravenous drug use), WHO stage III/IV HIV/AIDS, hepatitis B positivity, hepatitis C positivity, anemia, diabetes, and HIV-1 RNA viral load at baseline.

b: Reduced kidney function was defined as the development of an eGFR $<90 \mathrm{ml} / \mathrm{min} / 1.73 \mathrm{~m}^{2}$ during follow-up among patients who had an eGFR greater than or equal to $90 \mathrm{ml} / \mathrm{min} / 1.73 \mathrm{~m}^{2}$ at baseline.

c: Rapid kidney function decline was defined as an annual decline of $3 \mathrm{ml} / \mathrm{min} / 1.73 \mathrm{~m}^{2}$ or more. d: Represents the propensity score matched model.

\section{Figures}




\section{Figure 1}

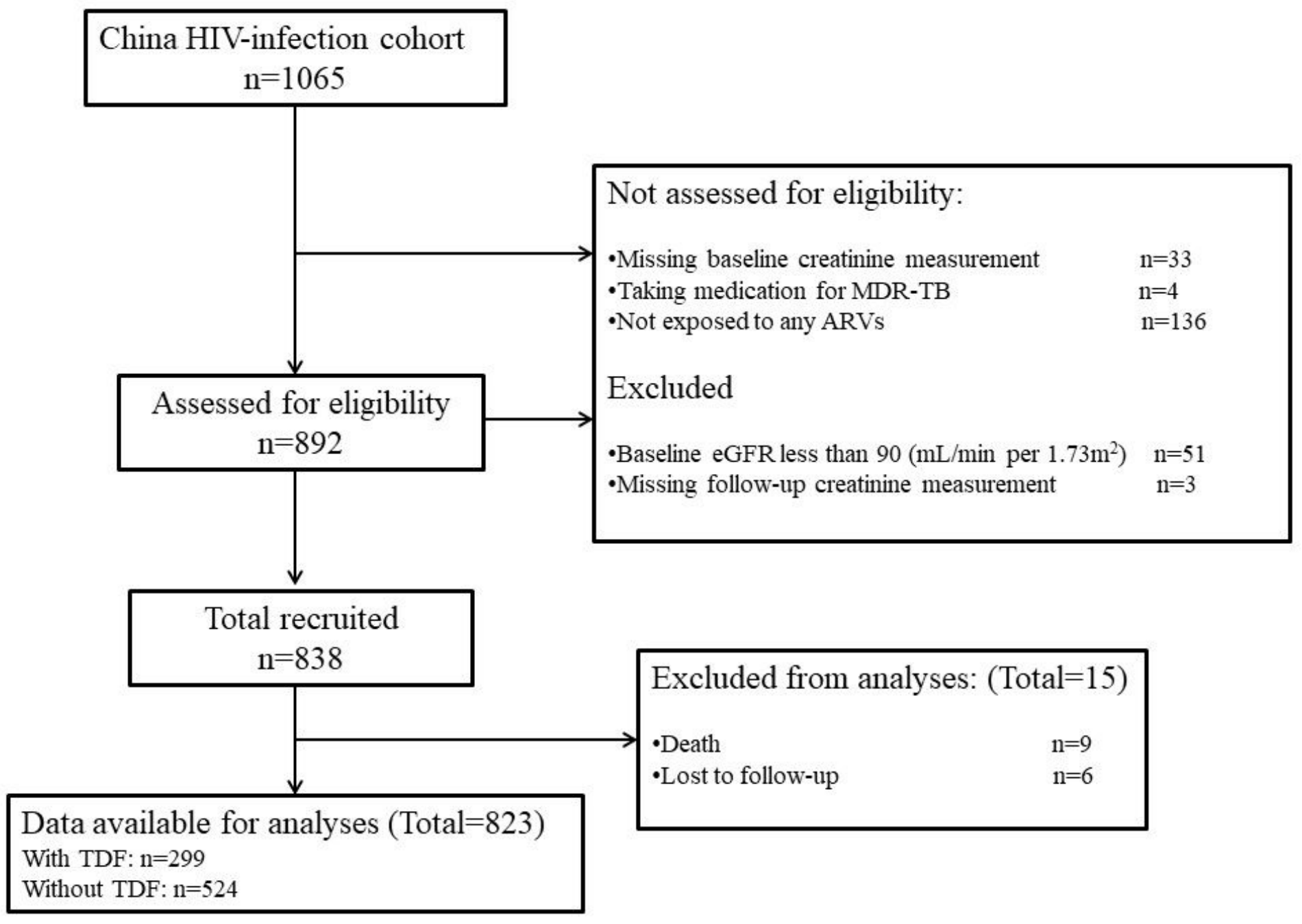

Figure 1

Study Flow Diagram 
Figure 2
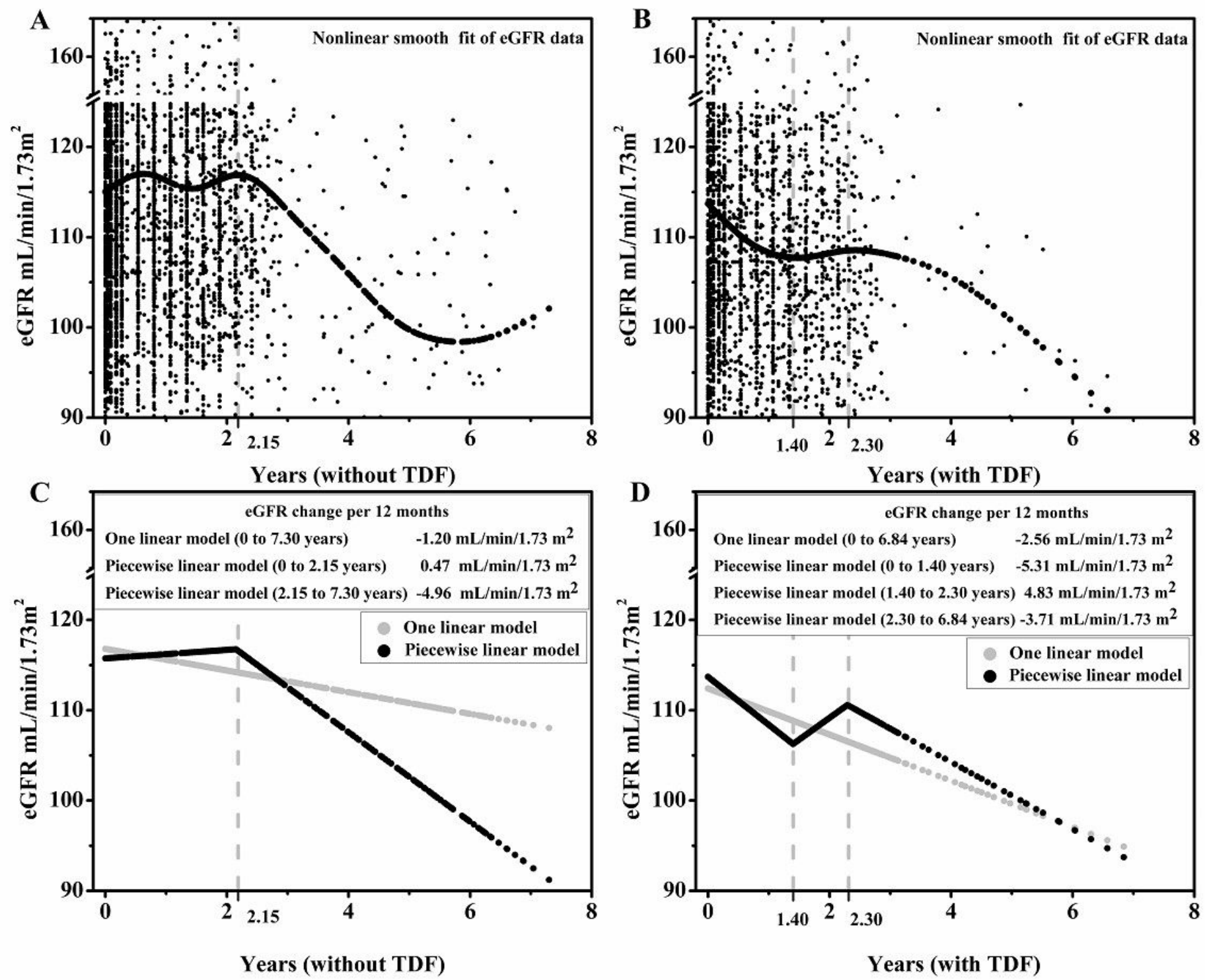

Figure 2

Nonlinear trajectory of eGFR among HIV-1-infected patients with or without TDF.

\section{Supplementary Files}

This is a list of supplementary files associated with this preprint. Click to download.

- supplement1.doc

- supplement2.tif

- supplement3.tif 